\title{
Pathogenetic Overlapping of Renovascular Hypertension Developed in a Child with Takayasu Arteritis:'One-clip, One and Half-kidney Model'
}

\author{
Su Jeong Lee, M.D. ${ }^{1}$ \\ Hee Sun Baek, M.D. ${ }^{1}$ \\ Hea Min Jang, M.D. ${ }^{1}$ \\ Hyung-Kee Kim, M.D. ${ }^{2}$ \\ Seung Huh, M.D. ${ }^{2}$ \\ Min Hyun Cho, M.D. ${ }^{1}$ \\ Department of Pediatrics', Department \\ of Surgery ${ }^{2}$, Kyungpook National \\ University School of Medicine, Daegu, \\ Korea
}

\section{Corresponding author:}

Min Hyun Cho, M.D.

Department of Pediatrics, Kyungpook

National University Medical Center

807 Hogukno, Buk-gu, Daegu 41404,

Korea

Tel: +82-53-200-2741

Fax: +82-53-200-2039

E-mail:chomh@knu.ac.kr

Received: 20 February 2016

Revised: 20 February 2016

Accepted: 20 February 2016

\footnotetext{
This is an open-access article distributed under the terms of the Creative Commons Attribution Non-Commercial License (http:// creativecommons.org/licenses/by-nc/4.0/) which permits unrestricted non-commercial use, distribution, and reproduction in any medium, provided the original work is properly cited.
}

There are two pathogenic models of renovascular hypertension (RVH) originating from renal artery stenosis. We noted a case of a boy who had severe hypertension with atrophic left kidney, hypertrophic right kidney, a segmental stricture of the abdominal aorta, and total occlusion of the right renal artery. Due to the atrophic change of the contralateral, unclipped left kidney, this patient presented with various clinical manifestations related to both models of pathogenesis of RVH occurring at the same time. We conclude that this patient presented with the middle stage of the two RVH pathogenetic models, so called the 'one-clip, one and halfkidney model.'

Key words: Pathogenesis, Renovascular hypertension, Takayasu arteritis, Reninangiotensin system

\section{Introduction}

Renovascular hypertension (RVH) is responsible for $5-10 \%$ of causes of hypertension in children ${ }^{1,2)}$. Diseases associated with renovascular hypertension in children include neurofibromatosis type I, tuberous sclerosis, Marfan's syndrome, Takayasu arteritis, polyarteritis nodosa and extrinsic compression due to tumor ${ }^{3}$. It has been reported that Takayasu arteritis is the most common vasculitis of the causes of RVH during childhood, especially in Asia and South Africa ${ }^{3,4)}$.

There are two pathogenesis models of RVH originating from renal artery stenosis; the 'one-clip, two-kidney model $(1 \mathrm{C} / 2 \mathrm{~K})$ ' and the 'one-clip, onekidney model $(1 \mathrm{C} / 1 \mathrm{~K})^{35)}$. Because there are clear differences of pathogenesis and optimal treatment between the two models, it is essential to clarify the dominant mechanism of RVH before initiating treatment. We disclose a case showing mixed manifestations of two pathogenesis models of RVH occurring at the same time.

\section{Case report}

A 12-year-old boy with intermittent headache due to severe hypertension 
was admitted to our hospital. His initial blood pressures (BP) of the extremities were 180/112 (right arm), 172/100 (left arm), and 160/100 (both legs) mmHg. Physical examination was non-specific except for abdominal bruit. Routine laboratory findings were within the normal ranges. Studies were done for secondary causes of hypertension and revealed elevated peripheral plasma renin activity (PRA) (>20 ng/ml/hour). Renal ultrasonogram revealed atrophic left kidney, hypertrophic right kidney and an abnormal flow pattern in right renal artery. Glomerular filtration rates on the $99 \mathrm{mTc}$-diethylenetriamine-pentaacetic acid scan were $64 \mathrm{ml} / \mathrm{min} / 1.73 \mathrm{~m}^{2}$ in the right kidney and $12 \mathrm{ml} / \mathrm{min} / 1.73 \mathrm{~m}^{2}$ in the left kidney. Computed tomography angiography showed a segmental stricture of the abdominal aorta, total occlusion of the right renal artery with collateral vessels through the adrenal artery (Fig. 1), severe stenosis of the right accessory renal artery and segmental stenosis of the proximal superior mesenteric artery, but a small relatively intact left renal artery (Fig. 2). This boy was diagnosed with Takayasu arteritis based on the diagnostic criteria of the American College of Rheumatology. The levels of PRA in the left, right renal veins and inferior vena cava were $25.02,28.89,23.22 \mathrm{ng} / \mathrm{ml} /$ hour, respectively. We carefully administered an angiotensin converting enzyme (ACE) inhibitor (enalapril $10 \mathrm{mg}$ ) because other antihyper-

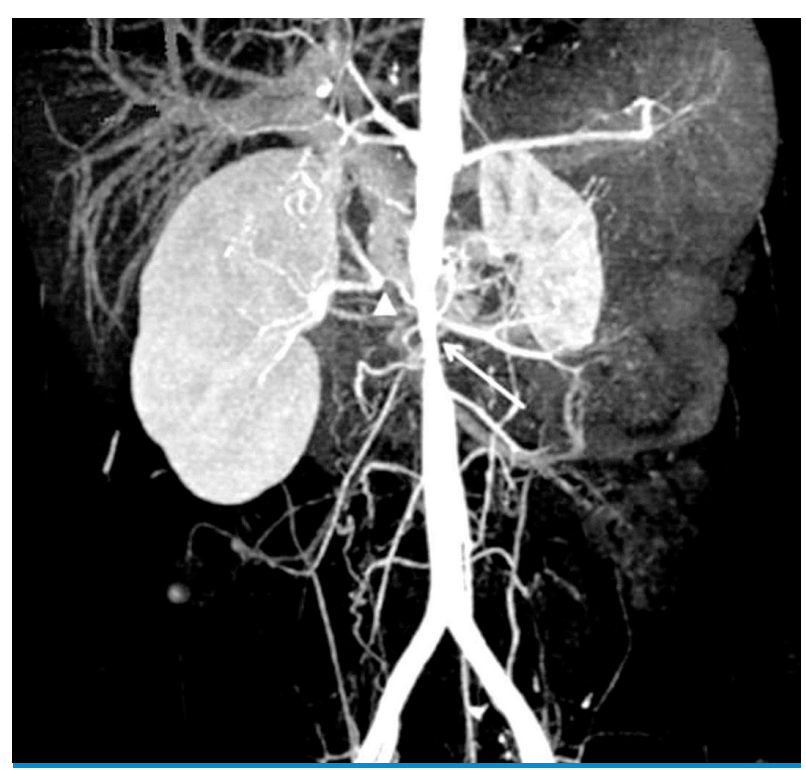

Fig. 1. Computed tomography angiography shows segmental stricture of abdominal aorta (white arrow), total occlusion of right renal artery with collateral vessels through the adrenal artery (white arrowhead). tensive drugs such as beta-blockers, calcium channel blockers, and vasodilators were not effective. His BP decreased 20-30 mmHg (systolic BP, 140-150 mmHg) just after ACE inhibition. Serum creatinine was maintained at normal levels. In order to decrease his BP within the normal range (systolic BP, under $120 \mathrm{mmHg}$ ), we added enalapril $10 \mathrm{mg}$ and an angiotensin-receptor blocker (losartan potassium $50 \mathrm{mg}$ ) under closed monitoring of his BP and renal function. One week later, his systolic BP decreased to about 120 $\mathrm{mmHg}$, but his serum creatinine increased to $2.6 \mathrm{mg} / \mathrm{dL}$.

This patient presented somewhat confused clinical manifestations related to two models of RVH occurring at the same time. Elevated PRA, a dramatic decrease in BP by an ACE inhibitor and unilateral renal artery stenosis in angiography were compatible with the $1 \mathrm{C} / 2 \mathrm{~K}$, whereas acute renal failure developed after additional administration of an ACE inhibitor and non-lateralization of renin activity between bilateral renal veins were compatible with the $1 \mathrm{C} /$ $1 \mathrm{~K}$. Thus, these manifestations could only be explained with the middle stage of the two models, so called the 'oneclip, one and half-kidney model (1C/1.5K)', originated from the atrophic change of contralateral, unclipped left kidney (Table 1).

Due to the limitation of medical treatments and consideration for the growth of height, we decided to perform surgical treatment involving insertion of an aortic stent and autotransplantation of the right kidney. Until now (at 5 years after operation), his BP and PRA level are maintained at normal levels without anti-hypertensive drugs. We are using only low-dose aspirin for the purpose of anti-

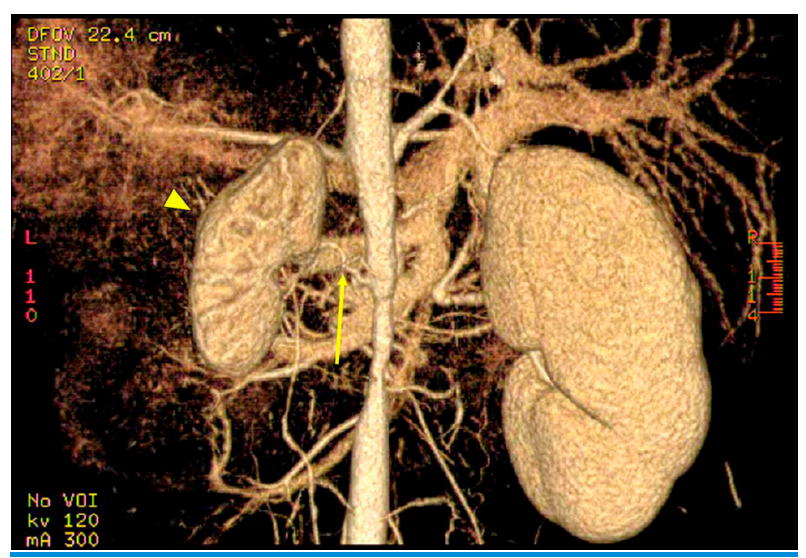

Fig. 2. Computed tomography angiography shows an atrophied left kidney (yellow arrowhead) with a small relatively intact left renal artery (yellow arrow). 
Table 1. Comparison of Clinical Manifestations according to the Pathophysiologic Mechanisms of Renovascular Hypertension

\begin{tabular}{lccc}
\hline & $1 \mathrm{C} / 2 \mathrm{~K}$ model & $1 \mathrm{C} / 1 \mathrm{~K}$ model & Our patient \\
\hline PRA level & Increased & Normal or decreased & Increased \\
Response to ACEi & Good & Good only after volume depletion & Good \\
Angiography & Unilateral renal artery stenosis & Bilateral renal artery stenosis & Unilateral renal artery stenosis \\
$\begin{array}{l}\text { Decrease of GFR after ACEi } \\
\text { Lateralization of renin activity } \\
\text { between both renal veins }\end{array}$ & In only stenotic kidney & Yes & Yes \\
\hline
\end{tabular}

Abbreviations: 1C/2K, one-clip, two-kidney model; 1C/1K, one-clip, one-kidney model; PRA, plasma renin activity; ACEi, angiotensin converting enzyme inhibitor; GFR, glomerular filtration rate.

coagulation to the aortic stent.

\section{Discussion}

There are two pathogenetic mechanisms of RVH developed by renal artery stenosis; $1 \mathrm{C} / 2 \mathrm{~K}$ and $1 \mathrm{C} / 1 \mathrm{~K}$. These mechanisms were created in animal models of renal artery stenosis with use of clips. The $1 \mathrm{C} / 2 \mathrm{~K}$ is developed from unilateral renal artery stenosis in two functional kidneys, whereas the $1 \mathrm{C} / 1 \mathrm{~K}$ from bilateral renal artery stenosis in both functional kidneys or single renal artery stenosis in one functional kidney ${ }^{5}$.

In the $1 \mathrm{C} / 2 \mathrm{~K}$, angiotensin-dependent manifestations such as prominent elevation of PRA, a dramatic decrease of BP and decrease of GFR in the stenotic kidney after administration of an ACE inhibitor can be presented. Reduced renal perfusion in the ipsilateral kidney due to unilateral renal artery stenosis provokes the activation of the renin-angiotensin system (RAS) and angiotensin II dependent hypertension, whereas, in the contralateral kidney, increased renal perfusion due to hypertension produces suppressed RAS and pressure natriuresis. In this case, the use of an ACE inhibitor is the choice of treatment to control $\mathrm{BP}$ before surgical correction. On the other hand, in the $1 \mathrm{C} / 1 \mathrm{~K}$, because reduced renal perfusion is developed in the single kidney with a clip or in both kidneys with each clip simultaneously, pressure natriuresis cannot be produced, thus RAS is inhibited due to volume expansion. Therefore, PRA is normal or low, and arterial pressure is reduced only after volume depletion. Also, in this model, the use of an ACE inhibitor is contraindicated due to the possibility of acute renal failure and the use of diuretics is recommended. In patients with two functional kidneys, a pathogenetic mechanism can be decided according to the role of the contralateral kidney without a clip. If the contralateral kidney has good function, the $1 \mathrm{C} / 2 \mathrm{~K}$ can be dominant, but if its function is not good, a pathogenetic mechanism of RVH can be changed to the $1 \mathrm{C} / 1 \mathrm{~K}$. In our patient, elevated PRA, a dramatic decrease of BP by an ACE inhibitor and unilateral renal artery stenosis in angiography were compatible with the $1 \mathrm{C} / 2 \mathrm{~K}$, whereas acute renal failure developed after additional administration of ACE inhibitors, and non-lateralization of renin activity between both renal veins were compatible with the $1 \mathrm{C} / 1 \mathrm{~K}$. We suggested that these confused, overlapped manifestations were developed by the atrophy of left contralateral kidney without a clip. If this kidney has no function, his manifestations would be compatible with the typical $1 \mathrm{C} / 1 \mathrm{~K}$. However, because this contralateral kidney had partial renal function and produced limited pressure natriuresis, he presented ambivalent manifestations, so called the ' $1 \mathrm{C} / 1.5 \mathrm{~K}$ '. Although we do not know the accurate reason of atrophic change in the left contralateral kidney without definite renal artery stenosis, there could be several possible causes including congenital hypoplasia or acquired atrophy due to Takayasu arteritis.

In conclusion, to understand the pathogenesis and choose the optimal treatment of RVH, it is important to clarify the dominant model of RVH developed by renal artery stenosis. We report on a child who was diagnosed with Takayasu arteritis and presented the middle stage of the two models of $\mathrm{RVH}$, so-called the ' $1 \mathrm{C} / 1.5 \mathrm{~K}$ '.

\section{Conflict of interest}

The authors report no conflicts of interest. The authors 
alone are responsible for the content and writing of the paper.

\section{References}

1. Wyszyńska T, Cichocka E, Wieteska-Klimczak A, Jobs K, Januszewicz P. A single pediatric center experience with 1025 children with hypertension. Acta Paediatr 1992;81:244-6.
2. Gill DG, Mendes de Costa B, Cameron JS, Joseph MC, Ogg CS, Chantler C. Analysis of 100 children with severe and persistent hypertension. Arch Dis Child 1976;51:951-6.

3. Tullus K, Brennan E, Hamilton G, et al. Renovascular hypertension in children. Lancet 2008;371:1453-63.

4. Hari P, Bagga A, Srivastava RN. Sustained hypertension in children. Indian Pediatr 2000;37:268-74.

5. Textor SC. Current approaches to renovascular hypertension. Med Clin North Am 2009;93:717-32. 